\title{
Variable Step Length Incremental Conductance MPPT Control Based on the Power Prediction
}

\author{
Yu Yunjun ${ }^{1,2,}$, Liu Tao ${ }^{1}$, Wang Shisheng ${ }^{1}$, Xin Jianbo $^{2}$, and Ou Yang Haibing ${ }^{1}$ \\ ${ }^{1}$ Information School of Nanchang University, Nanchang, Jiangxi, 330031, P.R. China \\ ${ }_{2}^{2}$ Jiangxi Electric Power Research Institute, Nanchang, Jiangxi, 330096, P.R. China
}

\begin{abstract}
The MPP of Photovoltaic power system undergoes migration or volatility under the influence of the external environments, especially light intensity changes. MPPT control is a very important method to increase the efficiency of the photovoltaic power generation system. But the existing variable step length incremental conductance method would produce misjudgment or even tracking failure when outside light intensity mutations. A variable step length incremental conductance MPPT control method based on power prediction has been proposed. This involves modeling, simulation and comparison of the different methods in the Matlab/Simulink environment. The proposed method can not only avoid misjudgments but can also track the MPP efficiently, improving the control accuracy compared with the variable step length incremental conductance method.
\end{abstract}

Keywords: MPPT, power prediction, variable step length incremental conductance method.

\section{INTRODUCTION}

When the external factors like outside light intensity, environment temperature and load change, the output voltage and current of the photovoltaic cells present non-linear characteristics, and their output power constantly changes [1].Therefore, tracking control is particularly important in order to maximize the output power of the system. At present, many MPPT [2] algorithms have been proposed at home and abroad, such as the disturbance observation method [3-6], incremental conductance method [7-8], the fuzzy control method [9], genetic algorithm $[10,11]$ and so on. The disturbance observation method shows rapid MPPT control, but there are oscillations which occur near the maximum power point, some fluctuations of the steady-state output waveform emerge and during the light intensity changes, it is also prone to miscarriage thus leading to tracking failure. Both the tracking speed and control precision of the incremental conductance method are good, but may also lead to miscalculations under the condition of external environment mutation. The fuzzy control is even a flexible control system having high precision steady-state and strong robustness. But in the PV MPPT control system, fuzzy control's adaptation ability is also limited and is easily oscillated under certain conditions.

The article $[12,13]$ describes the variable step length conductance increment method and perturbation method. The tracking speed and accuracy are all improved, but when the outside light intensity changes, it may cause misjudgment thus resulting in a miscalculated tracking effect. The article [12] provides MPPT method of forecast of power and

*Address correspondence to this author at the Information School of Nanchang University, Nanchang, Jiangxi, 330031, P.R. China; E-mail: yuyunjun@ncu.edu.cn voltage compensation. This method, however avoids the mistakes effectively, but does not give attention to the tracking speed and control precision. This paper therefore combines power prediction thought with the variable step incremental conductance method further proposing the variable step length incremental conductance MPPT control based method focused on the power prediction. Matlab modeling and simulation also proved the feasibility and effectiveness of the proposed method.

\section{THE NETWORK PRINCIPLE OF THE PV CELLS' ENGINEERING MATHEMATICAL MODEL}

The PV cells [14] are the device that convert solar energy into electrical energy. Its output power consists of a nonlinear function that takes account of the intensity of sunshine and the device junction's temperature. It works on the principle of semiconductor's P-N junction which involves receiving of the sun light and producing the photovoltaic. The solar PV battery's output current is related to the light intensity, temperature and area of the PV panel. Equivalent circuit diagram of the PV battery is shown in Fig. (1).

According to the equivalent circuit shown above, the mathematical expressions of the equivalent circuit of the PV battery's current and voltage's characteristics are listed as follows.

$$
\begin{aligned}
& I=I_{\mathrm{ph}}-I_{\mathrm{d}}-I_{\mathrm{sh}} \\
& U_{\mathrm{oc}}=\frac{\operatorname{AkT}}{\mathrm{q}} \ln \left(\frac{I_{\mathrm{sc}}}{I_{0}}+1\right) \\
& I_{\mathrm{d}}=I_{0}\left[\exp \left(\frac{\mathrm{q} U_{\mathrm{d}}}{\mathrm{AkT}}\right)-1\right]
\end{aligned}
$$




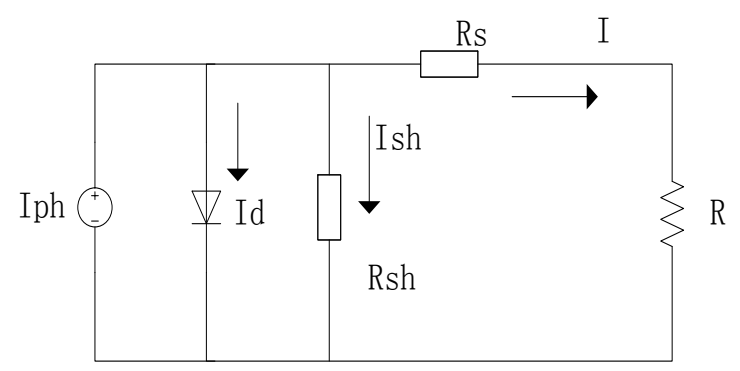

Fig. (1). Solar battery equivalent circuit.

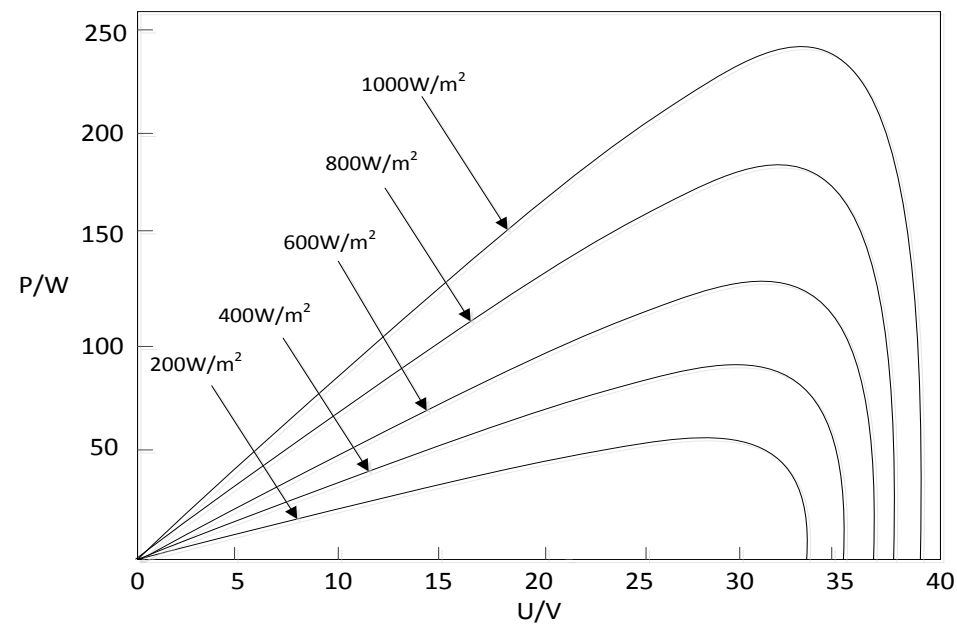

Fig. (2). The P-U curves of photovoltaic cells under different light intensity.

$$
\begin{aligned}
& I=I_{\mathrm{ph}}-I_{0}\left[\exp \left(\frac{\mathrm{q} U_{\mathrm{d}}}{\mathrm{AkT}}\right)-1\right]-\frac{U_{\mathrm{d}}}{R_{\mathrm{sh}}} \\
& U_{\mathrm{d}}=U_{\mathrm{oc}}+I R_{\mathrm{s}}
\end{aligned}
$$

where,

$I$---the output current;

$I_{p h}$---the photocurrent;

$I_{d}$---the equivalent diode current;

$I_{s h}$---the current of equivalent parallel resistance;

$U_{o c}$---the open circuit voltage of photovoltaic cells;

A ---the quality factor of two tubes;

$\boldsymbol{k}$---the Boltzmann constant, $1.38 \times 10-18 \mathrm{erg} / \mathrm{K}$;

$\boldsymbol{T}$---the environment's absolute temperature of photovoltaic battery;

$\boldsymbol{q}$---the electron charge, $1.6 \times 10^{-19} \mathrm{C}$;

$I_{s c}$---the PV battery internal short circuit current;

$I_{0}$--- the reverse saturation current of the P-N junction and isn't affected by the light intensity, approximation is to be a constant;
$U_{d^{---}}$the voltage of the equivalent diode;

$R_{s h}$--- the equivalent parallel resistance;

$R_{s}$--- the equivalent series resistance.

Because the PV batterys' internal equivalent parallel resistance $R_{\text {sh }}$ is large that makes the $I_{\text {sh }}$ value of 0 , so its effect can be neglected. The output characteristics of PV cells can be expressed as:

$I \approx I_{\mathrm{ph}}-I_{0}\left[\exp \left(\frac{\mathrm{q} U_{\mathrm{d}}}{\mathrm{AkT}}\right)-1\right]$

The article [15] provides the CS6M20-250W simulation model for the solar photovoltaic cell panel. Its basic electrical parameters are the short-circuit current $I_{\mathrm{sc}}=9.0 \mathrm{~A}$, the open circuit voltage $U_{\text {oc }}=36.9 \mathrm{~V}$, the maximum power pointcurrent $I_{\mathrm{m}}=8.34 \mathrm{~V}$, the maximum power point voltage $U_{\mathrm{m}}$ $=30.0 \mathrm{~V}$, the temperature of the environment $\mathrm{T}=25^{\circ} \mathrm{C}$. The $\mathrm{P}-\mathrm{U}$ simulation characteristic curves diagram is shown in Fig. (2).

As it can be seen from the simulation graph, the output characteristics of the PV battery, P-U curve is a single peak curve and in different light intensities, the maximum power point constantly shifts. 


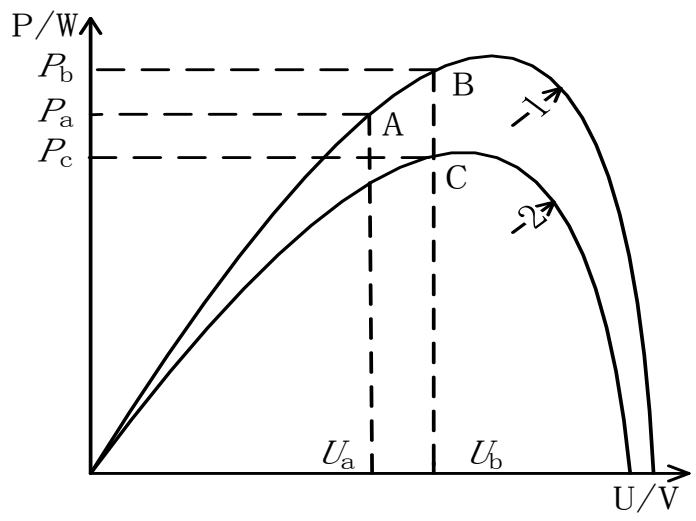

Fig. (3). Incremental conductance method misjudgment schemes.

\section{THE VARIABLE STEP LENGTH INCREMENTAL CONDUCTANCE MPPT METHOD}

The variable step length incremental conductance MPPT method has been proposed to solve the contradictions between the tracking speed and precision of the traditional fixed step incremental conductance method. The P-U curve of the PV array is a single peak curve, so there will be $d P / d U=0$ at the maximum power point. The articles [8] and [9] proposed a variable step incremental conductance method, its principle can be simply described as: when the tracking point is away from the maximum power point, it can use a larger step size in order to accelerate the tracking speed and when the tracking point is near the maximum power point, the tracking precision is improved by using a small step.

Although the variable step length incremental conductance method largely improves the tracking speed and precision of the photovoltaic system, but when the outside light intensity mutates, the PV battery working point sequence does not appear in a single curve; instead it is composed of different characteristic curves' working points [16-18] thus misjudgment is caused very easily and the tracking speed and precision are affected. Fig. (3) shows the possible misjudgment schematic diagram when outside light intensity mutates. The main reason that causes misjudgment lies in the sampling values that are obtained in different sampling times having changed outside environment, thus the sampling points are located in different power-voltage curves. Assuming that at some moment, the PV system works in A point, the voltage and power are $U_{a}$ and $P_{a}$; assuming that the light intensity does not change, the voltage fluctuates to point $\mathrm{B}$, at this time the power meets $P_{b}>P_{a}$, and next time the voltage will continue to change in the direction of increasing voltage. But, if the light intensity decreases, by the curve 1 to 2 , the working point will be moved to the point $\mathrm{C}$ where there will be $P_{c}<P_{a}$ and misjudgment will appear at this interval. This will make the voltage change in the direction of decreasing voltage causing tracking failure.

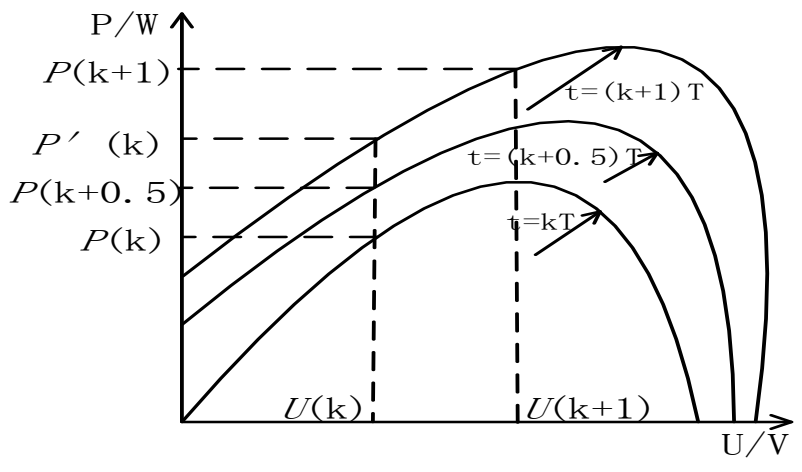

Fig. (4). Power prediction schemes.

\section{THE VARIABLE STEP LENGTH INCREMENTAL CONDUCTANCE MPPT CONTROL BASED ON THE POWER PREDICTION}

PV system operates in different P-U curves. The light intensity mutation is a continuous process that obtains the power before and after the voltage disturbance in P-U characteristic curves in approximately same light intensity. When the light intensity mutation trend forecasts the direction of change in the P-U curve, P-U characteristic curve is thus obtained in approximately same light intensity. On this basis, the predict data is adopted to conduct calculation of the variable step incremental conductance method and avoid misjudgment effectively. Power prediction method is simply the estimated power value from the first sampling time's power to the next sampling time's P-U curve.The principle of the power prediction method is shown in Fig. (4) (Assume that the light intensity is increased).

The principle analysis is as follows. At kT moment, the voltage is $U(\mathbf{k})$ and its power is $P(\mathbf{k})$. At this time, there is no reference to voltage perturbation. At $(\mathrm{k}+1) \mathrm{T}$ moment, there is an increase in sampling and the measured power is $P(\mathrm{k}+0.5)$.Then the $(\mathrm{k}+1) \mathrm{T}$ moment's voltage $U(\mathrm{k}+1)$ and power $P(\mathrm{k}+1)$ are measured. When there is a high sampling frequency and the external light intensity changes evenly, accordingly the output power is directly proportional to the light intensity, the predicted power $P^{\prime}(\mathrm{k})$ is:

$P^{\prime}(\mathrm{k})=2 P(\mathrm{k}+0.5)-P(\mathrm{k})$

The predicted power $P^{\prime}(\mathrm{k})$ and $P(\mathrm{k}+1)$ can be seen from the power in P-U curve that under the same light intensity, the perturbation step is $|(d P / d U) / P|$ and $[P(k)-P(k-1)] /[U(k)-U(k-1)]$ is used to express $d P / d U$. At this time, the criterion of variable step incremental conductance method becomes:

$[P(k)-P(k-1)] /[U(k)-U(k-1)]=0$

It is obvious that the obtained predicted power $P^{\prime}(\mathrm{k})$ and $P(\mathrm{k}+1)$ through power prediction method can be seen as two test data from the same characteristics, so it can avoid the misjudgment effectively. 


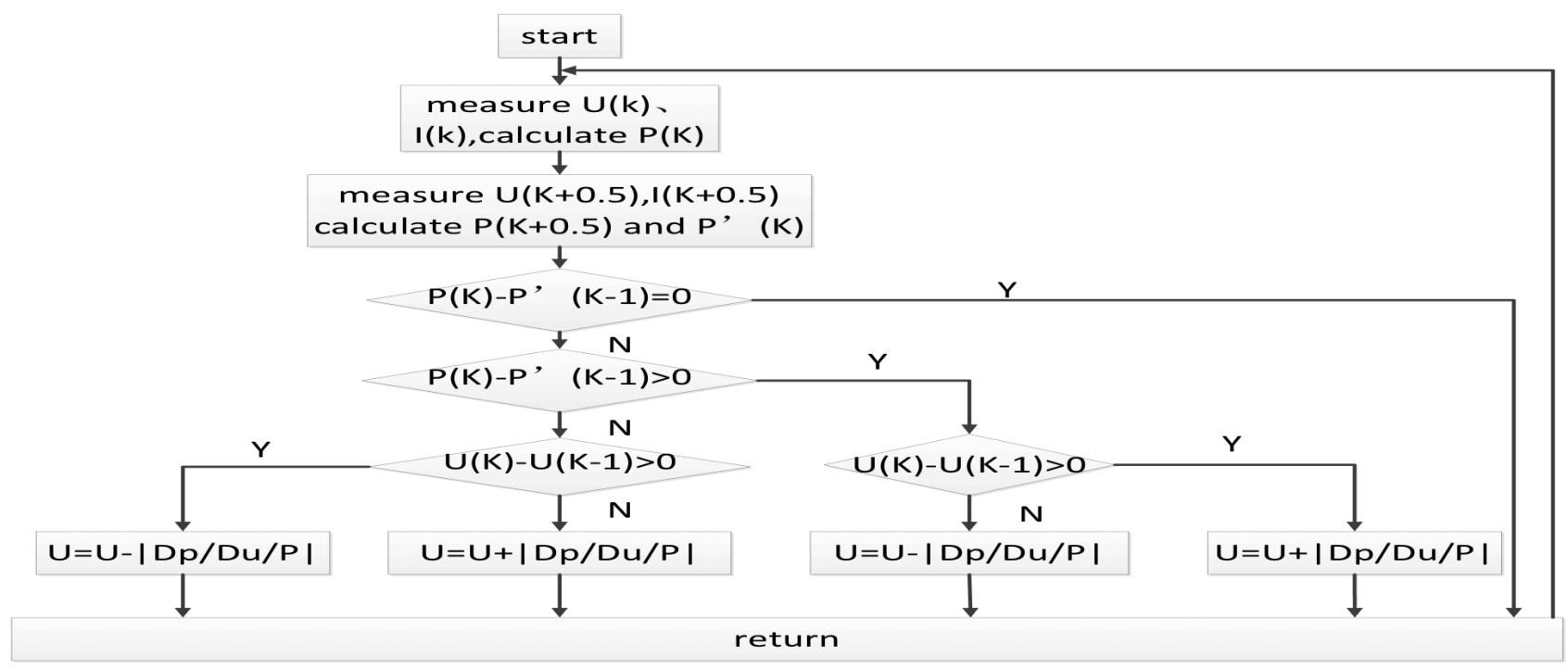

Fig. (5). Flow chart of variable step length incremental conductance MPPT control based on the power prediction.

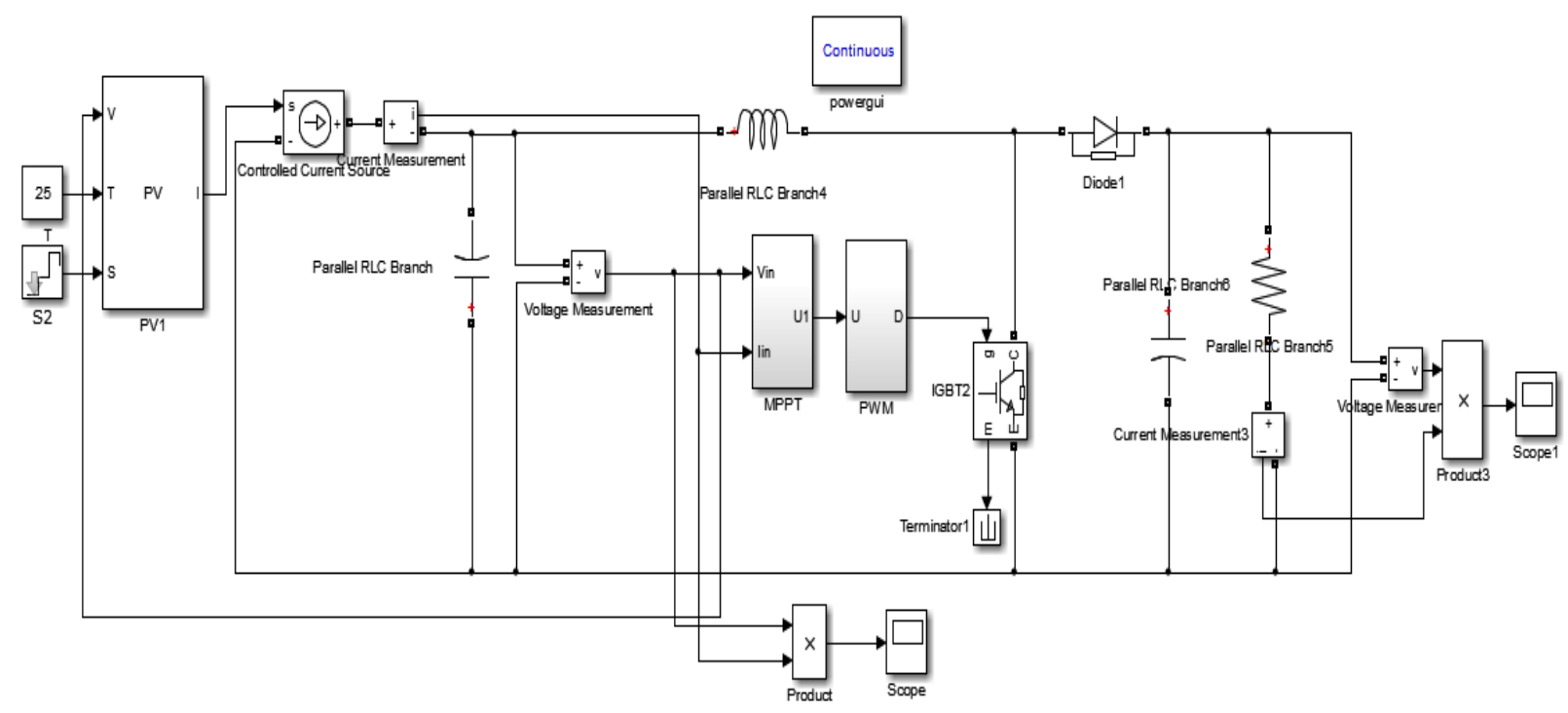

Fig. (6). simulation model.

On the basis of the power prediction method to solve the misjudgment, the variable step incremental conductance method that is used in this paper is based on the photovoltaic array's $|(d P / d U) / P|$ to adjust the step size. When it is away from the maximum power point, the $|(d P / d U) / P|$ is relatively large, which can speed up the system tracking speed. When reaching near the maximum power point, the $|(d P / d U) / P|$ is relatively small, which can improve the tracking accuracy.

The flow chart of the variable step length incremental conductance MPPT control based on the power prediction is shown in Fig. (5).

\section{MODELING AND ANALYSIS OF SIMULATION RESULTS}

In order to verify the validity of the method, the simulation model is established in Matlab/Simulink as shown in Fig. (6). The boost circuit parameter is set to $C_{1}=220 \mu \mathrm{F}, C_{2}$ $=3000 \mu \mathrm{F}, L=800 \mathrm{mH}, R=10 \Omega$. The current and voltage signal sampling period is $0.001 \mathrm{~s}$.

Fig. (7) shows the above two methods that when the light intensity changes, the disturbance voltage variation of each sampling time point, in the figure insets is partial enlargement in the vicinity of $0.6 \mathrm{~s}$. When the light intensity in $0.6 \mathrm{~s}$ suddenly changes from $1000 \mathrm{~W} / \mathrm{m}^{2}$ to $800 \mathrm{~W} / \mathrm{m}^{2}$; according to the foregoing description, it should increase the disturbance voltage after $0.6 \mathrm{~s}$. From the partial enlargement in 


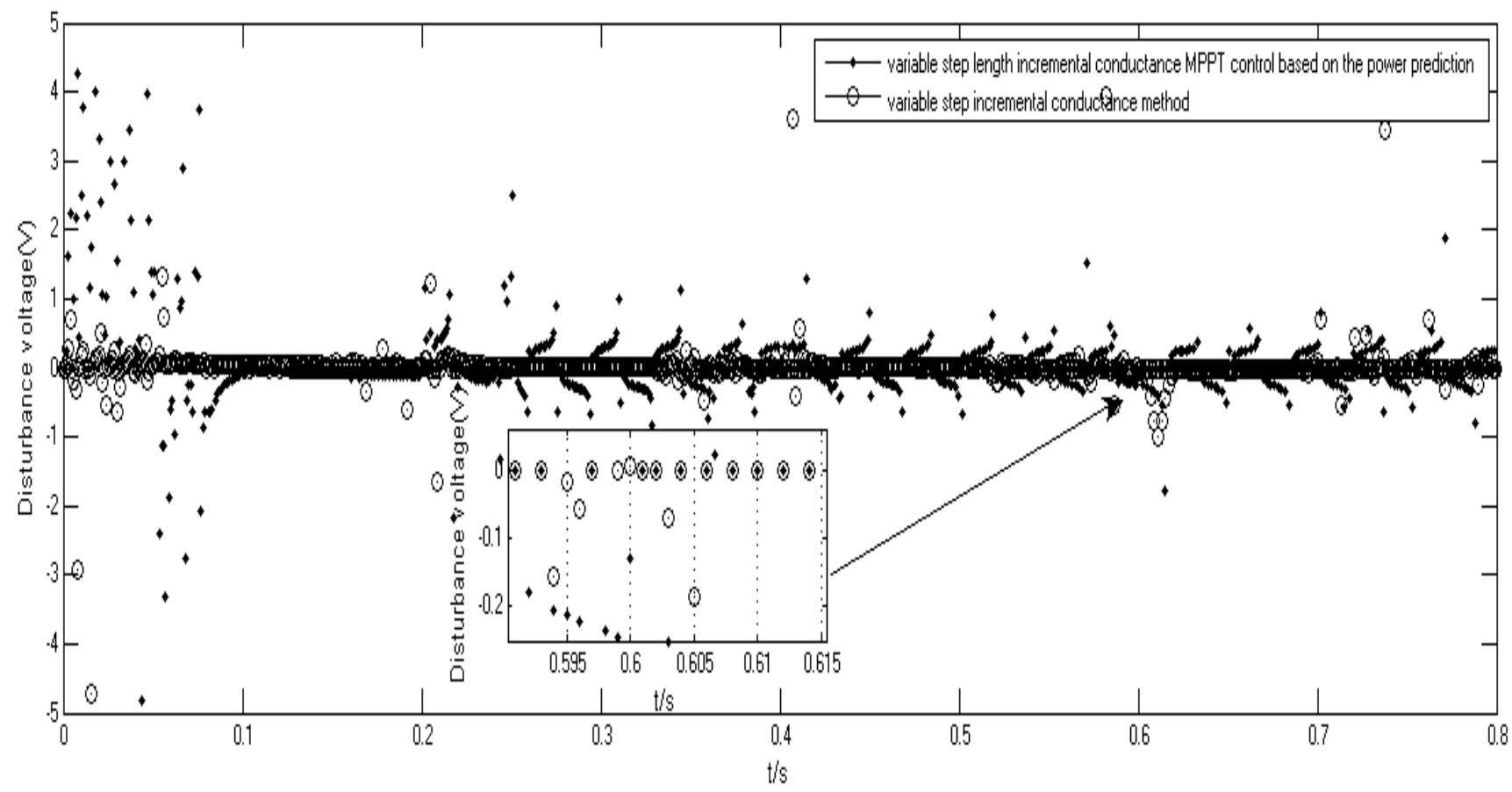

Fig. (7). Disturbance of sampling points change chart.

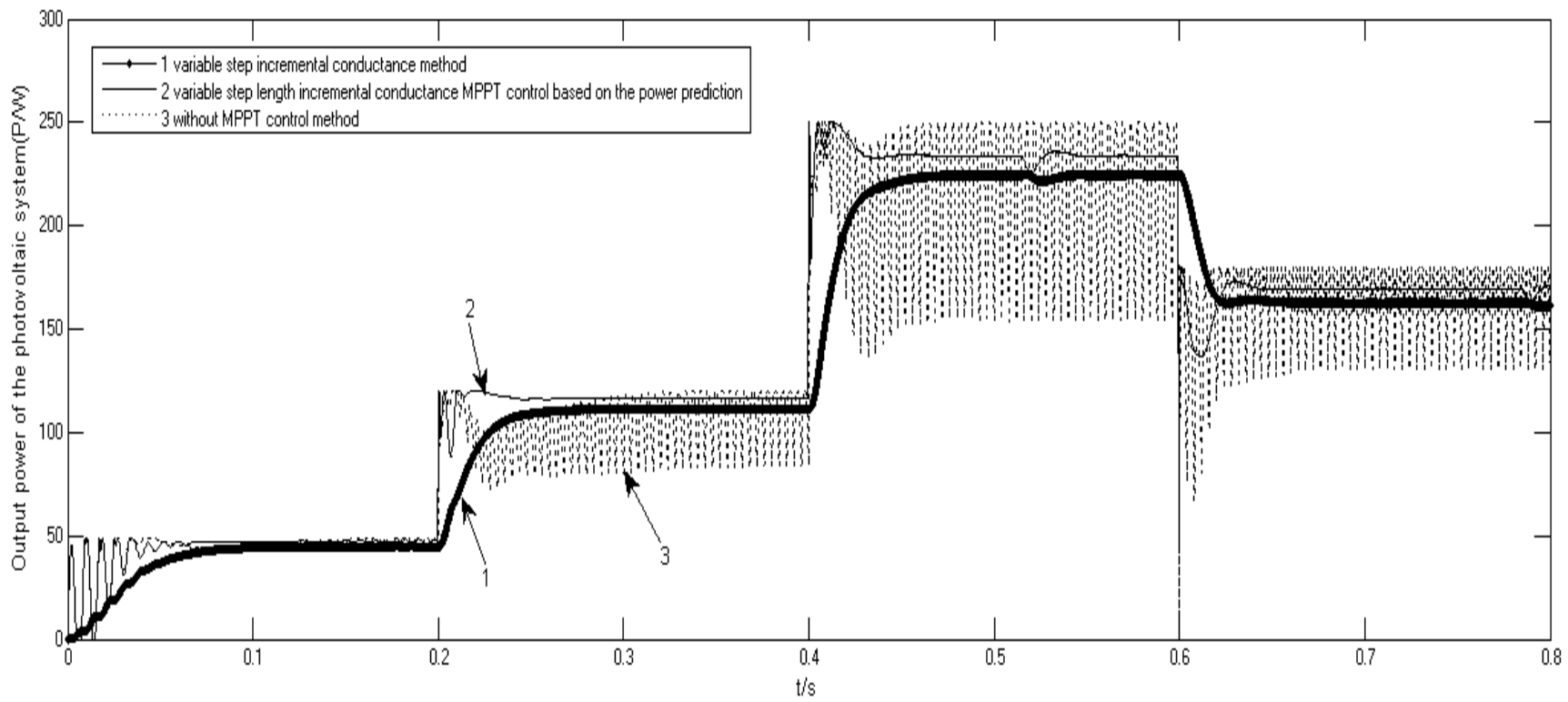

Fig. (8). The simulation waveform of the light intensity changes.

Fig. (7) we can see that there are 5 sampling points from $0.6 \mathrm{~s}$ to $0.605 \mathrm{~s}$, in the $0.601 \mathrm{~s}$ sample point, if it did not use the power prediction method, the disturbance voltage decreased and the disturbance direction changed, leading to misjudgment. But if it used the power prediction method, the disturbance voltage increased and the disturbance direction remained unchanged. So it is proven that the power prediction method could avoid misjudgment when the light intensity mutates.

\subsection{Constant Temperature, Light Intensity Changes}

The external environment is normal temperature 25 , light intensity $\mathrm{S}$ changes from $300 \mathrm{~W} / \mathrm{m}^{2}$ to $600 \mathrm{~W} / \mathrm{m}^{2}$ at $0.2 \mathrm{~s}$ and continues changing from $600 \mathrm{~W} / \mathrm{m}^{2}$ to $1000 \mathrm{~W} / \mathrm{m}^{2}$ at $0.4 \mathrm{~s}$; finally, it reduces to $800 \mathrm{~W} / \mathrm{m}^{2}$ at $0.6 \mathrm{~s}$., The three different MPPT control method's waveforms tracking are received as shown in Fig. (8). Through simulation, we can see that when the light intensity changes, without the MPPT control method, the output power's oscillation range is very large 
Table 1. Testing data.

\begin{tabular}{|c|c|c|c|}
\hline \multirow{2}{*}{ Tracking Method } & $\begin{array}{c}\text { Respond Time That Arrive at } \\
\text { the Maximum Power Point /s }\end{array}$ & $\begin{array}{c}\text { The Actual Average } \\
\text { Output Power /W }\end{array}$ & $\begin{array}{c}\text { Percentage Error of the Actual Average Out- } \\
\text { put Power and Perfect Power /\% }\end{array}$ \\
\hline \hline \multirow{3}{*}{$\begin{array}{c}\text { Variable step length incremental } \\
\text { conductance MPPT method }\end{array}$} & 0.235 & 110.6 & 4.1 \\
\cline { 2 - 4 } & 0.441 & 228.6 & 4.8 \\
\cline { 2 - 4 } & 0.634 & 174.2 & 4.3 \\
\hline \multirow{2}{*}{$\begin{array}{c}\text { Variable step length incremental } \\
\text { conductance MPPT control based } \\
\text { on the power prediction method }\end{array}$} & 0.219 & 116.5 & 2.2 \\
\cline { 2 - 4 } & 0.421 & 235.4 & 2.0 \\
\hline
\end{tabular}

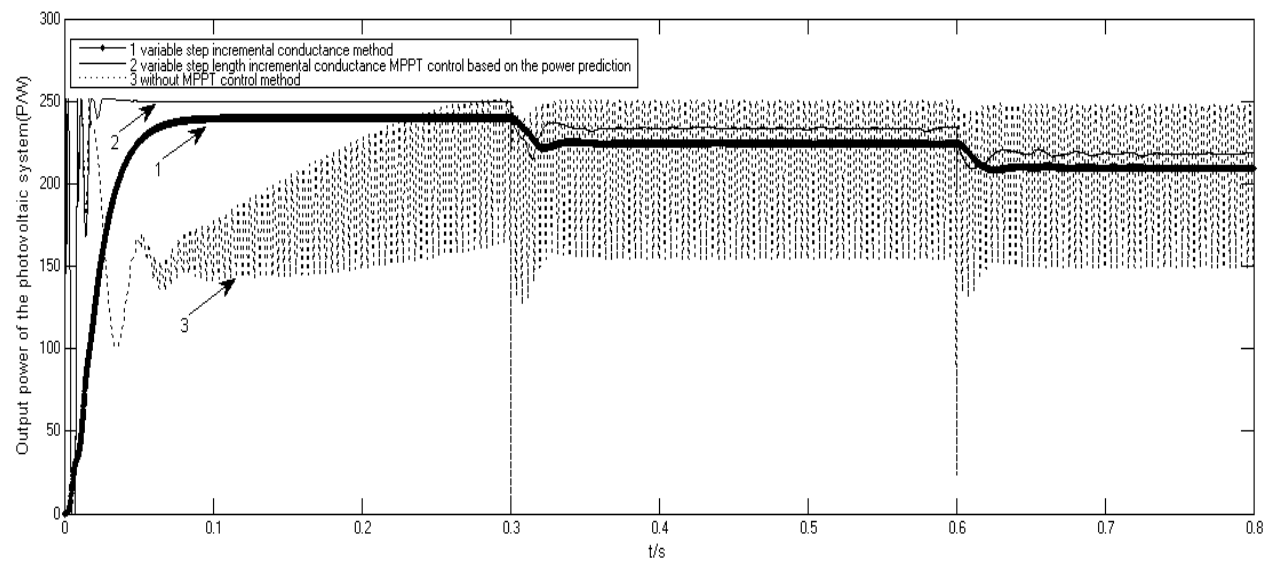

Fig. (9). The simulation waveform of environmental temperature changes.

and very unstable; the variable step length incremental conductance MPPT method can avoid spikes, but its tracking speed is not very good.When the variable step length incremental conductance MPPT control based on the power prediction compared to the variable step length incremental conductance MPPT method, the former method can track the new maximum power point quickly having a good control precision. According to the above simulation experiment, the experimental data of different time points are obtained after light intensity changes, as shown in Table $\mathbf{1}$.

An important index which measures whether the MPPT control method is good or not is the MPPT algorithm's tracking efficiency $\eta_{\text {MPPT }}$. Its calculation method is:

$\eta_{\mathrm{MPPT}}=\frac{\int_{0}^{\mathrm{t}} P_{\mathrm{pv}-\max }(\mathrm{t}) \mathrm{dt}}{\int_{0}^{\mathrm{t}} P_{\mathrm{pv}-\mathrm{mppt}}(\mathrm{t}) \mathrm{dt}}$

where,

$P_{\mathrm{pv}-\mathrm{mppt}}(\mathrm{t}) \mathrm{dt}$--- the output power of photovoltaic system that uses the MPPT control method;

$P_{\text {pv-max }}(\mathrm{t}) \mathrm{dt}$--- the output power in the MPP.

When the outside light intensity changes as described above, the result that uses the variable step incremental con- ductance method is $96.24 \%$, while the result that uses the variable step length incremental conductance MPPT control based on the power prediction is $98.47 \%$. Thus, the efficiency of the variable step length incremental conductance MPPT control based on the power prediction is higher, its Dvalue is $2.23 \%$.

According to the above data and analysis, when the light intensity changes, the variable step length incremental conductance MPPT control method based on the power prediction arrives faster at the MPP than the variable step incremental conductance method and the former method's percentage error of the actual average output power and perfect power is lower than the latter. So in the inhibition of oscillation at the maximum power point, the maximum power output and the tracking speed. are enhanced. Therefore, the variable step length incremental conductance MPPT control method based on the power prediction has obvious advantages.

\subsection{Constant Light Intensity, the Temperature Changes}

The external light intensity remains in the $1000 \mathrm{~W} / \mathrm{m}^{2}$, but the temperature $\mathrm{T}$ changes from $0^{\circ} \mathrm{C}$ to $25^{\circ} \mathrm{C}$ at $0.3 \mathrm{~s}$ and continues to change from $25^{\circ} \mathrm{C}$ to $40^{\circ} \mathrm{C}$ at $0.6 \mathrm{~s}$. Finally, the three different MPPT control method's waveforms tracking are received as shown in Fig. (9). Without the MPPT control method, the waveform has great fluctuation; The variable 
step incremental conductance method inhibits fluctuation, but its tracking speed is not ideal. When the variable step length incremental conductance MPPT control based on the power prediction is compared to the variable step length incremental conductance MPPT method, it is observed that the former method can track the new maximum power point quickly and has a good control precision.

\section{CONCLUSION}

The variable step length incremental conductance MPPT control based on the power prediction proposed in this paper arrived at $0.219 \mathrm{~s}, 0.421 \mathrm{~s}$ and $0.623 \mathrm{~s}$ at the MPP when the environment temperature was constant while the external light intensity changed [16-21]. When compared to the variable step incremental conductance method, it was observed that the former could track the MPP more faster and the percentage error of the actual average output power and perfect power were $2.2 \%, 2.0 \%$ and $1.9 \%$ respectively. Thus, the control precision improved. In the condition of the external light intensity being constant while the environment temperature changed, the MPP arrived respectively at $0.321 \mathrm{~s}$ and $0.624 \mathrm{~s}$. Therefore, both the tracking speed and efficiency are improved by this method compared to the variable step incremental conductance method.

\section{CONFLICT OF INTEREST}

The authors confirm that this article content has no conflict of interest.

\section{ACKNOWLEDGEMENTS}

This work was financially supported by the National international science and technology cooperation project (2014DFG72240); National Science and technology support program (2013BAA01B01); NSFC (51467013), Key Technology R\&D Program of Jiangxi Province (2013 BBE50105) and Nanchang University Create Project (20140403038).

\section{REFERENCES}

J. Yang, S. Qiang, and L. Wen-hua, "Practical simulation model of photovoltaic cells in photovoltaic generation systems and simulation”, Power System Technology, vol. 34, pp. 198-202, 2010.

[2] Z. Bi-wei, C. Feng-huang, and W. Wu, "Analysis and research of MPPT algorithm for a single-stage PV grid-connected power generation system", Transactions of China Electrotechnical Society, vol. 26, pp. 90-96, 2011

[3] H. Feng-hai, Y. Wei, and Z. Wen-yan, "Analysis and improvement of MPPT disturbance observer method for PV system”, Power System Protection and Control, vol. 42, pp. 110-114, 2014.

[4] N. Femia, G. Lisi, and G. Petrone, "Distributed maximum power point tracking of photovoltaic arrays: novel approach and system analysis", IEEE Transactions on Industrial Electronics, vol. 55, pp. 2610-2621, 2008.
[5] C. Ya-ai, Z. Jing-hua, and L. Jin, "Application of gradient variable step size mppt algorithm in photovoltaic system", Proceeding of the CSEE, vol. 34, pp. 3156-3161, 2014.

[6] X. Feng, "A MPPT control for photovoltaic power system based on the fuzzy control and variable step length disturbance observation method of power prediction", Computer Measurement and Control, vol. 22, pp. 414-417, 2014.

[7] B. Ubudhi, and R. Pradhan, "A comparative study on maximum power point tracking techniques for photovoltaic power systems", IEEE Transactions on Sustainable Energy, vol. 4, pp. 89-98, 2013.

[8] K. S. Tey, and S. Mekhilef, "Modified incremental conductance MPPT algorithm to mitigate inaccurate responses under fastchanging solar irradiation level", Solar Energy, vol. 101, pp. 333342, 2014.

[9] L. Li-qun, W. Zhi-xin, and G. Lin-feng, "MPPT control based on improved fuzzy method for distributed hybrid wind-solar power enerating systems", Power System Protection and Control, vol. 39, pp. 70-76, 2011.

[10] X. Jun-min, W. Dong-yun, and L. Yan-bin, "Research on a maximum power point tracking with DRP based on genetic algorithm", Power System Protection and Control, vol. 38, pp. 43-46, 2010.

[11] S. Daraban, D. Petreus, and C. Morel, "A novel MPPT (maximum power point tracking) algorithm based on a modified genetic algorithm specialized on tracking the global maximum power point in photovoltaic systems affected by partial shading", Energy, vol. 74, pp. 374-388, 2014

[12] X. Feng, Z. Xiang-jun, and X. Yu, "Application of Current Prediction-Based Incremental Conductance Method in PV MPPT", Process Automation Instrumentation, vol. 6, pp. 31-34, 2014.

[13] F. Wang, Z. Lin, and G. Ke, "Research on engineering analytical model of solar cells", Transactions of China Electrotechnical Society, vol. 26, pp. 211-216, 2011.

[14] W. Xiao-feng, Z. Yan-fei, and Y. Yun-jun, "Comparison Study on Photovoltaic Cell Engineering Mathematical Model", Computer Simulation, vol. 31, pp. 113-117, 2014.

[15] C. A-lian, F. Li-na, and D. Chun-shui, "Modeling of photovoltaic array based on support vector machines under partial shaded conditions", Transactions of China Electrotechnical Society, vol. 26, pp. 140-146, 2011.

[16] S. Li, A. Attou, Y. Yang, and D. Geng, "A maximum power point tracking control strategy with variable weather parameters for photovoltaic systems with DC bus", Renewable Energy,vol. 74, pp. 478-488, 2014.

[17] N. Femia, G. Lisi, and G. Petrone, "Distributed maximum power point tracking of photovoltaic arrays: novel approach and system analysis", IEEE Transactions on Industrial Electronics, vol. 55, pp. 2610-2621, 2008.

[18] L. Gao, R. A. Dougal, and S. Liu, "Parallel-connected solar PV system to address partial and rapidly fluctuating shadow conditions", IEEE Transactions on Industrial Electronics, vol. 56, pp. 1548-1556, 2009.

[19] E. Karatepe, E, Syafaruddin, and T. Hyama, "Simple and highefficiency photovoltaic system under non-uniform operating condition", IET Renewable Power Generation, vol. 4, pp. 354-368, 2009.

[20] H. Taheri, Z. Salam, and K. Ishaque, "A novel maximum power point tracking control of photovoltaic system under partial and rapidly fluctuating shadow conditions using differential evolution", In: IEEE Symposium on Industrial Electronics \& Applications (ISIEA), Penang: IEEE, pp. 82-87, 2010.

[21] V. Phimmasone, Y. Kondo, and T. Kamejima, "Evaluation of extracted energy from PV with PSO-based MPPT against various types of solarirradiation changes", In: International Conference on Electrical Machines and Systems (ICEMS), Incheon: IEEE, pp. 487-492, 2010. 